\title{
Development of Dynamic Modular Curriculum System Driven by Typical Work Tasks---A Case of Tourism Major of High Vocational College
}

\author{
Yunqin Liu \\ Humanity tourism department of Hunan vocational college of commerce, Changsha, Hunan, \\ 410205, China \\ Lyq521125@126.com
}

Keywords: Typical work-task driven; The dynamic modular curriculum system; Development; Tourism Specialty of higher vocational college

\begin{abstract}
The traditional subject curriculum model is deconstructed through the in-depth research of the tourism industry and Tourism Speciality of vocational education. With the typical tasks-driven of tourism industry professional post-group and specific career scene for the module, the dynamic modular curriculum system development model driven by the typical is set upon the basis of establishing the theoretical model of research, technology route model and the dynamic knowledge modular models initially. It will provide technical support and reference for Tourism Specialty and other majors in higher vocational education curriculum reform and construction.
\end{abstract}

\section{典型工作任务驱动的动态模块式课程体系的开发 研究一一以高职旅游专业为例}

\author{
刘韵琴 \\ 湖南商务职业技术学院人文旅游学院, 中国 湖南 长沙 410205
}

Lyq521125@126.com

摘要: 在深入调研旅游产业的基础上, 对传统的学科式课程模式的进行解构, 以旅游行业职 业岗位群的典型工作任务为驱动, 具体的职业情景为依托, 通过对课程开发模型研发理论模 型、技术路线模型和动态模块构建模型的建开发, 开发出以旅游服务典型工作任务为驱动的 动态模块式课程开发模式, 为高职旅游专业课程改革和建设和提供技术性支持, 并为其他文 科类专业课程的建设和开发提供借鉴。

关键词：典型工作任务驱动；动态模块式课程体系; 开发; 高职旅游专业

\section{1. 引言}

自上个世纪 80 年代以来, 我国自主培养的旅游类毕业生还不能满足社会需求, 主要原因是毕 业生对口就业率低。近年来最突出的问题在人才培养的效果与市场需求之间的距离大, 最直接 原因是旅游类专业课程设置存在着诸多问题。总体来说, 当前的课程体系还基本延续了学科 体系的课程模式, 普遍存在着课程目标定位不准; 课程体系设置与具体岗位需要联系性不强; 课程设置从内容到形式都比较死板, 缺乏适应市场变化的灵活性; 课程实施过程中学生普遍 学习积极性不高, 极大的制约了高职旅游教育的进一步发展, 影响了社会对高职旅游类专业 人才的认可度。 


\section{2. 高职旅游专业任务驱动课程体系研究现状}

工作任务及过程系统化课程也叫学习领域课程方案 [1 ], 是在德国职业教育学家劳耐尔提出 的以 “设计导向” 的指导思想下，逐步形成的课程开发模式，是德国 “双元制” [2]职业教育 改革的核心内容之一。目前, 目前国际国内十分著名的以工作过程为驱动的课程模式如德国 的 “双元制”，国际劳工组织 MES，澳大利亚的 TAFE 等 [3 ] [4 ], 某种程度上就代表了国际 课程体系开发的最前沿水平, 也是上个世纪 70 年代以来国际职业教育大发展的三个代表时段。 在国内, 基于工作课程的课程体系引进的时间相对较晚, 主要以姜大源为代表的教育研究团 队在借鉴德国的 “双元制” 课程模式，再根据中国职业教育发展的实际状况而开发的新的课 程模式。纵观我国职业教育发展史, 从中国的职业教育启蒙人黄元培到现在的姜大源、刘育 锋和卢双盈等当代职教专家, 从课程模式到职教师资队伍的培养与建设, 无不走着借鉴和模 仿的道路, 没有真正意义上形成具有中国特色的职教之路, 尤其是课程体系开发和人才培养 的理念, 教育行政部门的管理体系也是沿用了党政管理体系, 常常是上级要求严苛, 下级拼 死努力实现上级的意图, 整个职业教育界真实的情况是比较紊乱, 辛苦的广大职教领域的老 师和学生。到 2008 年, 一场由行业专家和职业教育研究者发起的全国性的职业教育教育教学 改革论坛上, 经过激烈的讨论, 达成我国职业教育领域内的两个内容的共识: 一是解构原有 的学科型课程体系, 按照职业行动领域, 重构新的具有职教特色的课程体系。二是确定以实 际工作领域的需求为准则, 以构成职业行领域的典型工作任务为主线, 重新构建各种知识和 能力模块。三是重新组织和设计职业教育的教育教学内容, 探索新的教育教学方法 [5] [7]。 本次论坛, 从理论到实践都肯定了以工作任务为驱动的, 工作过程为基础的系统化高职课程 模式的重要性。

工作任务及过程驱动的课程模式是吸收了项目一体化、基于工作过程等课程模式的特长, 将 学生的个人学习能力、职业能力与个性与典型工作任务、典型工作任务充分联系在一起, 并 以满足产业经济发展和社会需求为前提下，重视个人在业导向的职业教育大目标下个人职业 生涯可持续发展的问题以及职业教育本质属性、职业教育可持续发展等问题。这是我国职业 教育中具有颠覆性的理念, 把职业教育和个人成长紧密结合起了, 还原了职业教育的本质和 人文服务性。几年的时间, 高职院校在借鉴这种课程模式的基础上对传统学科体系进行解构与 重构, 取得了一定的成绩, 但大多是仅限工科专业。相比之下, 旅游类专业课程体系的改革还 有待于进一步探索。主要存在诸如课程标准模糊不清, 课程结构体系老化、与市场基本脱节, 培养目标不准确等等致命的技术问题。要彻底解决上述问题, 就必需在旅游类专业课程体系 的建设上有所突破和创新。

\section{3. 典型工作任务驱动的高职旅游专业动态模块式课程体系开发研究}

3.1. 高职旅游类专业课程开发存在的问题

3. 1.1 高职院校自主开发课程的意识不强、专业教师的积极性不高

高职旅游类专业人才培养和课程开发等方面存在的问题集中反映是院校自主开发专业课程的 意识不强, 缺乏长效的课程建设和开发的保障机制。作为院校课程开发的主体的高职院校教 师, 参加课改、课程开发和建设的积极性却不高。一方面是国家对学院、学院对教师还都没 有形成一系列激励课程开发以及进行新课程评价。另一方面而很多学校领导则认为重新构建 课程体系既有技术上的难度，又有教学条件和资金投入方面的制约。

3.1 .2 课程体系的改革严重滞后旅游职业教育和旅游产业的发展

当前, 高职学院的课程体系大多是承袭传统基础理论教育, 已经远远滞后于我国高等职业教 育和旅游产业的发展状况。随着我国旅游业的进一步发展, 旅游院校如何充分利用旅游市场 发展为契机, 不断地探索、调整、改进、完善, 推动新的适应旅游经济发展形势的课程建设 和开发，培养出更为实用高职旅游人才成为当务之急。 
3.1 .3 高职旅游专业人才培养目标定位不准确, 课程很难体现高职特色

数据显示, 大多数高职学生对自己的个人定位是模糊的, 人才培养目标与本科院校同名专业 培养目标没有区别。这种培养目标定位的不准确, 直接导致课程设置的不合理。缺少对学生 面向岗位群的分析, 缺少面向工作岗位的典型工作任务的分析, 与实践的联系不紧密, 因此 无法让学生根据自身的特点体验未来的工作环境。在设置课程的时候, 一味追求全面, 以为 这就是可以拓宽学生的知识面, 提高学生就业竞争力, 其实看似 “全才” 的课程体系, 却导 致了课程内容的杂乱, 宽而不深, 缺少应有的高职特色。

3.1.4 课程内容还主要依托于教材, 课程评价方式单一, 实施方法落后 过度依赖教材, 限制了老师的课程教学的创造性, 单一滞后的评价体系, 让老师很难放手去 钻研或者自主重组教学内容。加上市场上的旅游教材良莠不齐, 缺乏本地旅游业发展的特色 教师授课时侧重教材上理论的知识传授, 缺少对学生职业素养方面的养成教育, 很难激发学 生的学习兴趣。

3.1.5 课程开发与旅游行业和企业的深度融合不够, 工学结合特色不突出

目前高职院大多数课程目标缺少针对性、目的性, 多数课程由学校教师根据毕业生面向岗位 群的知识能力素质设置, 属于以职业能力分析为导向进行课程开发, 忽视了工作的整体性, 忽视了对学生的全面发展, 课程体系缺少了职业特色, 基本上是空对空、理论对理论。工学 结合特色不明显, 学生的职业素养无法得到基于具体工作情景的提高, 直接后果是一方面大 量旅游管理专业学生对口就业难，而另一方面旅游行业招不到合适人才的怪异现象。

3. 2. 典型工作任务驱动的高职旅游专业动态模块式课程体系研究目标

典型工作任务驱动的高职动态模块化课程体系, 力求突破学科课程体系的束缚, 从旅游行业 实际工作岗位群的典型工作任务出发, 按完成实际工作任务所需要的知识技能, 将学习过程、 工作过程与学生的个性能力发展联系起来, 设计出动态教学模块和安排教学活动, 该课程模 式显著特征是教学过程与工作过程紧密相连, 融理论模块与动态实践模块于一体, 为学生提供 了体验典型工作过程的学习机会, 适应高职学生思维特征, 能够激发高职学生学习兴趣, 有利 于学生构建知识能力体系 [8] [9]。课程研究必须实现三个工作目标: 一是重构高职旅游类专 业课程体系。即打破传统学科型课程体系, 针对旅游业典型工作岗位群中的实际工作任务, 重新构建以一系列旅游大类专业核心课程为中心的课程体系, 并按实际工作过程来开发和重 新设计动态的旅游知识和能力学习模块、课程体系和课程标准。二是重组教学内容: 解构传 统的以学科知识逻辑为主线、专业理论知识为主体的教学内容, 针对旅游业经营管理的典型 实际工作任务, 以职业活动为主线, 以培养职业能力为本位, 重新组织和设计教学内容。三 是重新设计旅游专业课程教学实施的具体情景和教学方法, 使整个课程体系不再局限于学科 体系, 而是以典型工作任务为驱动, 以动态职场实际工作情景为教学模块的课程体系, 使高 职旅游类专业课程从理论到实践都形成以工作任务为驱动的动态模块的课程模式。

3. 3. 典型工作任务驱动的高职旅游专业动态模块式课程体系开发模型的构建

3. 3.1 研发理论模型的构建

典型工作任务驱动的高职旅游专业动态模块课程体系研究立足于旅游企业的实际工作岗位群, 依托典型的工作任务而展开的。根据学习领域中的认知理论, 构建典型工作任务驱动的高职 旅游专业动态模块式课程体系研发理论模型（图 1)，形成课程模式开发的理论依据。 


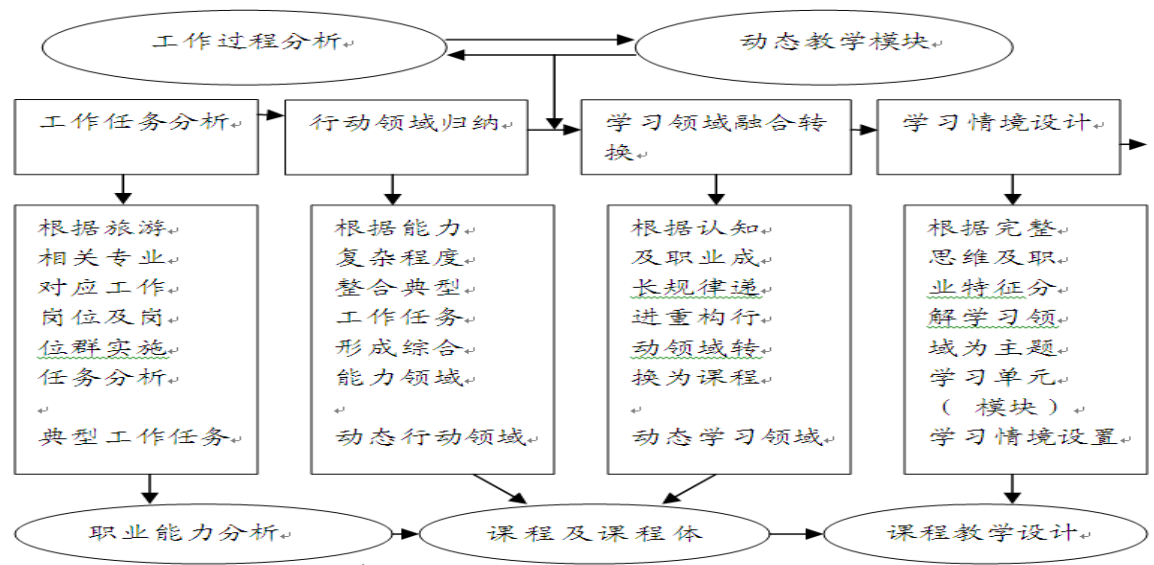

图 1 典型工作任务驱动高职旅游专业动态模块课程模式开发的研发理论模型

\section{3.2 课程体系开发的技术路线模型的开发}

典型工作任务驱动的高职旅游专业动态模块式课程体系的构建与实施, 必须沿着七个步骤展 开 [2] [10], 首先艳着眼于社会经济形势, 则要有教学目标, 行动导向原则的确立。在完成教 学设计与组织、学习情境的设计、教学论和方法论的设计后, 进行学习领域的转换, 再进行 行动领域的归纳和总结, 最后才能完成课程体系的构建与实施（图 2)。

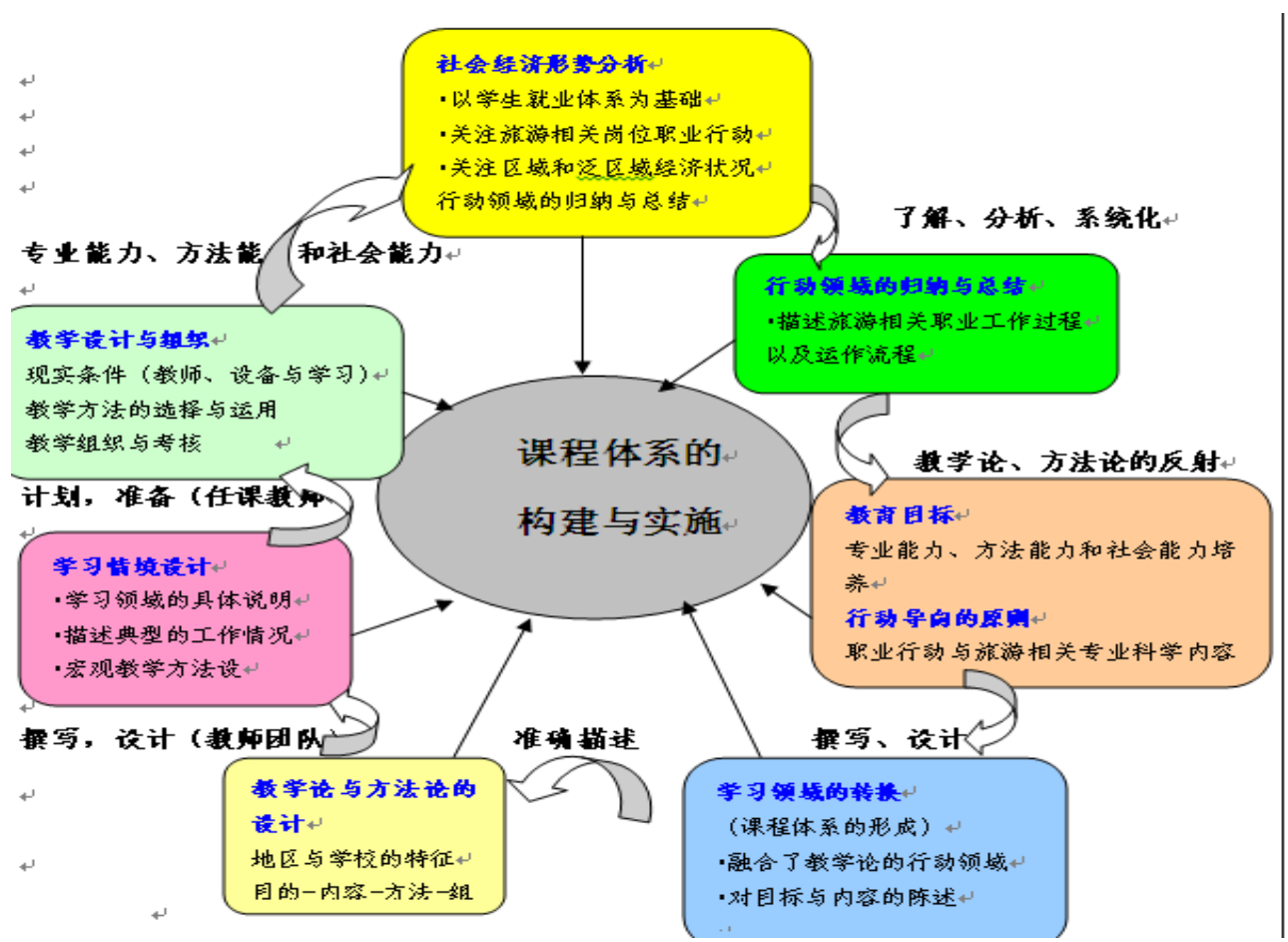

图 2 典型工作任务驱动的高职旅游类专业课程体系研究技术路线模型

3. 3. 3 以导游服务为例的典型工作任务驱动的高职旅游专业动态模块式课程模型开发

3. 3. 3. 1 联合企业、行业和职业教育专家, 根据旅游产业职业岗位群对人才知识、能力、技 能和素养方面的需求进行调研，对高职旅游人才培养的知识能力模块和对应的工作过程中的 实际情景进行对接性定位（图 3)。以旅游活动中导游服务工作这份典型工作任务为例，一个 合格的导游员必须具备 8 大工作知识和能力模块。任何一个模块都是相对独立而又紧密相连, 教师可以根据具体工作过程需要和学生学习的实际情况, 动态的安排和组合学生的教学内容, 设计教学情境, 完成教学评价任务。 


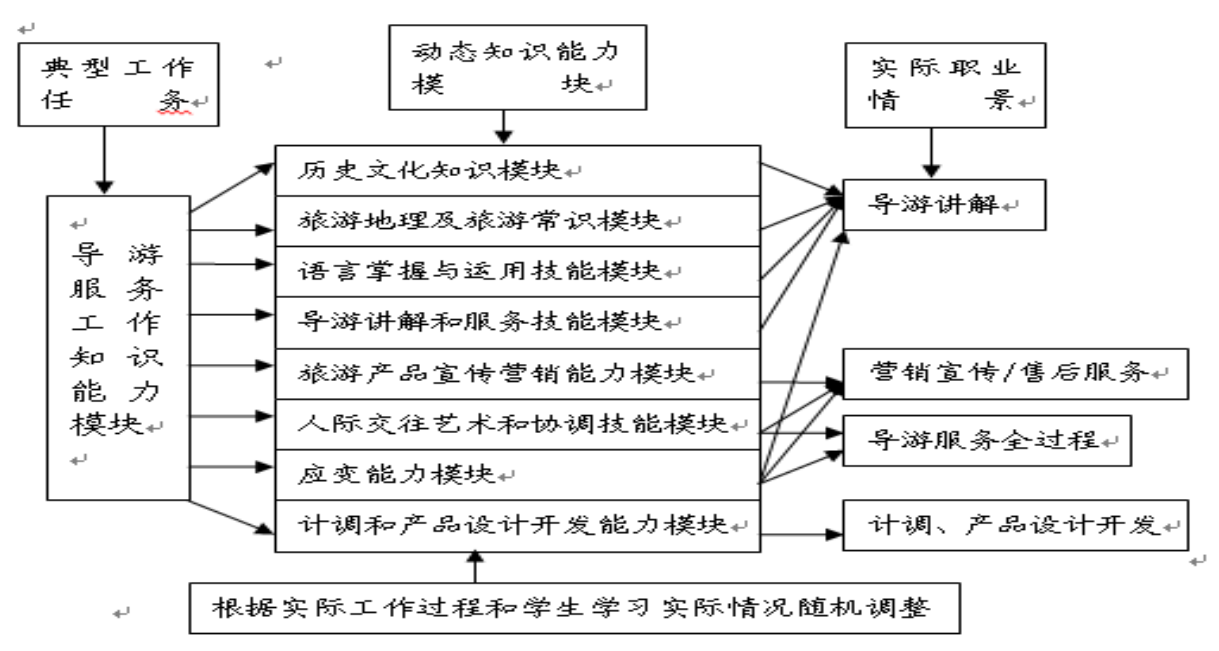

\section{图 3 典型旅游服务工作任务: 导游服务工作要掌握的八大动态知识能力模块及对应的实际工 作情景模型}

3. 3. 3. 2 解构高职旅游类专业课程原有的学科课程体系, 研发和重构以导游服务、旅行社管 理与服务及景区服务与经营三大旅游管理典型工作任务为核心，根据它们典型职业情景（如 旅行社经营服务中的计划与调度工作情景）工作过程需要和学生实际学习能力和兴趣而进行 调整的动态知识能力模块群。

3. 3. 3.3 开发旅游管理三大典型工作任务所涉及的四大专业核心课程《旅游概论》、《导游实 务》、《旅行社经营管理》和《景区服务与经营》动态知识能力模块课程标准。

3. 3. 3.4 构建以三大旅游管理工作任务为核心, 以 $\mathrm{N}$ 个实际典型职业情景为基础的动态模块 式的三大旅游管理动态课程体系。

3. 3. 3.5 进行新课标和新课程教学体系试点实践研究, 并开发相应的课程教学实施评价与保 障机制。

\section{4. 典型工作任务驱动的高职旅游专业动态模块式课程体系研究结果}

4. 1.1 通过对以典型工作任务驱动的高职旅游专业动态模块课程体系的研究, 可期待解决新 的旅游产业和市场的市场需求下, 根据各种旅游职业岗位群的特点, 在解构传统学科课程体 系的前提下如何设置基于典型工作任务的和工作实际情景的动态知识能力模块群科学合理设 置的问题，科学开发和制定高职旅游类专业课程标准。

4. 1.2 通过对典型工作任务驱动的高职旅游专业动态模块课程体系的研究, 解决如何以工作 任务为驱动, 以典型职业情景为基础的高职动态模块群课程体系构建问题。

3.1 .3 能充分利用课堂和实践环节资源, 进行典型工作任务驱动的高职旅游专业动态课程体 系的实证研究和推广实施的建设问题。

4. 1.4 通过研究, 打破高职旅游类专业的现有的传统的学课程体系, 完成高职旅游专业核心 课程知识的重构, 以典型工作任务驱动的动态模块课程体系, 完成一系列高职旅游类专业核 心课程的知识、能力模块的开发, 在根据具体的教学目标进行课程教学的实施和评价。

\section{5. 结语}

通过对旅游产业、市场和行动研究领域的分析, 通过对旅游职业各种岗位群的典型工作任务 的深入分析, 在解构传统学科型课程模式的基础上, 分析出当前高职旅游类专业课程开发和 实施的主要的症结, 进行以典型工作任务驱动, 对高职旅游专业动态模块式课程体系模式的 研究和探索, 建立起以典型工作任务驱动的动态模块课程的构建和开发的三个基础模型, 解 
决类高职旅游类专业课程长期以来在开发过程中繁琐、滞后和成本高昂的问题, 为后期以典 型工作任务为驱动的旅游类乃至其他类课程的构建、开发和实施提供了富有实践意义的工具。

\section{6. 致谢}

【基金项目】本研究受湖南省教育教改重点项目（ZJA2013018）、湖南省教育科学十二.五规 划课题（XJK014CZY039）基金支持。

\section{参考文献}

[1] 姜大源.当代世界职业教育发展趋势研究[M], 2013.8, p.(145-145).

[2] 刘占明. 基于工作过程导向的高职旅游类专业课程体系创新研究, 河北师范大学硕士论文 [D], 2009.8,20, p.(14-20).

[3] 徐玉岩. 基于项目驱动的高职 “于项目驱动的高职与 Linux 操作系统” 课程教学改革,计 算机教育[J],2010.9, 18, p.(25-27).

[4] 姜大源.再释德国双元制职业教育体系，中国职业技术教育2013.1,p.(21-30)

[5] Information on http://www.kmk.org [EB/OL].

[6] Information on http://www.bibb.de [EB/OL].

[7] Bundes institute fuer Berufsbildung Daler Report Zum Berufsildung Sbericht 2012. Informationen und Analysen ZurEntwicklung. Derberuflichen Buildung Bonn, 2012.

[8] 蒋方纯.现代职业教育课程教学构建策略, 2013深圳国际社会科学、心理学和管理学大会, 2013.1, p.(231-236).

[9] 卢丽宁. 导游职业技能竞赛机制下的高职旅游专业实训教学研究---以《广西导游基础知识》 课程为例, 南宁职业技术学院[J], 2015.5, p.(67-70).

[10] 赵晓芳, 李丽.信息化时代高职旅游专业课程体系构建研究,教育理论与实践[J] 2015.36, p.(29-31)

\section{Acknowledgement}

This research was financially supported by the 2013Important Research Project of Higher Education Reform in Hunan (ZJA2013018) and the 2014Educational Scientific Subject of Hunan Twelfth Five Years Plan (XJK014CZY039J).

\section{References}

[1] Jiang Dayuan. The Present Research on the Developing Tendency of the Contemporary Vocational Education in the World, 2013. 8, p.145-145

[2] Liu Zhanmin. Creative Research on course system of Major of High-level Vocational Tourism Based on Working Process, Heibei Normal University, 2009. 8, 20, p.14-20

[3] Xu Yuyan. Tending Reform of Windows and Linux Operarting Systems in higher Vocation Education Based on Project Driven. Computer Education, 2010.9, p.25-27

[4] Jiang Dayuan. Three Basic Questions to Build a Modern Vocational Education System, Guangzhou Vocational Education Forum 2012.1,p.5-7

[5] Information on http://www.kmk.org[EB/OL] 
[6] Information on http://www.bibb.de[EB/OL]

[7] Jiang Fangchun. Modern Vocational Education Course Teaching Building Strategy, 2013 International Conference on Psychology,Management and Social Science(PMSS 2013), 2013.1, p.212-215

[8] Bundes institute fuer Berufsbildung Dalerreport Zum Berufsildungs Bericht 2012. Informationen und Analysen Zur Entwicklung. Derberuflichen Buildung Bonn, 2012

[9] Lu Lining. Research on Practical Teaching of Tourism Program in Vocational Collegesunder Tour Guide Vocational Skill Competition Mechanism--A Case Study of Basic Knowledge for Guangxi Tour Guides, Nanning Technical Vocational College, 2015.5, p.67-70

[10]Zhao Xiaofang, Li Li. Research on the Construction of Curriculum System of Higher Vocational Tourism Major in the Information Age. Theory and Practice of Education, 2015.36, p.29-31

作者简介: 刘韵琴 (1970-), 女, 湖南永州, 教授, 主要研究方向: 职业教育, 生态旅游。 邮箱: 1yq521125@126.com 